\title{
Networks and the Future: \\ A New Methodological Approach \\ To Envision and Create the Network Society of Tomorrow
}

\author{
By \\ José A. Rodríguez Díaz, Dr., PhD \\ Department of Sociology and Organizational Analysis \\ University of Barcelona
}

\begin{abstract}
This paper aims to illustrate how the combination of Network Analysis and Futures Studies becomes a powerful instrument for envisioning and analyzing futures and social change. The study of three cases shows network analysis becoming an analytical tool in futures studies while, at the same time, acquiring the dimension of change and dynamics steaming from the futurist perspective.
\end{abstract}

Keywords: future studies, network analysis

\section{Introduction}

The interplay between network analysis, both as a theoretical conception and a methodological approach, and futures studies -also in its conceptual and technical aspects- offers a new and powerful opportunity to better understand futures and social change that I would like to explore briefly in these pages.

Network analysis [1, 2] has often been mentioned as one of the available instruments (or part of the toolbox) in futures studies $[3,4]$ and/or in futureoriented analyses and methods [5, 6, 7, and 8]. Its use, however, has not yet been fully explored. Social networks, relationships and interactions, constitute a new form of capital, a new form of organization and even a new form of identity and action [9, 10]. We live in a network society where networks and relationships have become an essential and defining aspect of our past, present and future $[11,12]$. To the extent that social and individual life cycles transpire over networks, their structures and dynamics become predictive or explanatory of how things and/or behaviors will be in any given historical moment. As a 
result, they will enable us to make predictions about probable (likely) futures, envision possible futures, and define and build preferable (desirable) futures.

In terms of world view or cognitive position, both Network Analysis and Futures Studies stand at the leading edge of science [13, 14]. Not only are their theoretical and methodological approaches new, but they also address social phenomena or dimensions that are novel, dynamic and future-directed. In this respect, the two approaches already exhibit a number of overlaps. Moreover, researchers in both areas now find themselves positioned at the cutting edge as they lead a transformation of the social sciences [3].

If the two approaches, separately, have great power and potential to illuminate new realities and dynamics and to transform how the social sciences work, then together their potential multiplies in magnitude. Given the growing importance of relational and network capital in the unfolding structure and dynamics of society in the twenty-first century, their inclusion as a piece of knowledge is clearly useful for envisioning the future in at least three dimensions:

- Action is taken through networks, with the result that understanding the characteristics of networks will aid our understanding and identification of likely actions. Networks shape and drive action and therefore the future.

- Action is taken in networks, leading us to address a new unit of analysis. The focus is no longer on individual actions but on the actions of new social organizations: mega-networks.

- Networks are a quintessential example of shifting territories, embodying new organizational forms that can change and adapt continuously. As a consequence, they represent spaces and organizational forms that enable and create the future.

The combination of futures studies and network analysis becomes a powerful instrument for envisioning and analyzing futures. It is turning social network analysis into an analytical instrument in futures studies and, in turn, endowing it with the dimension of change and a sense of the future. The combination makes it possible to introduce key aspects of networks into social network analysis, namely dynamics. This brings forth the dimension of cause 
and effect into network analysis and opens the door to assessing the impact of certain features (centrality, clustering, etc.) in the dynamics and future of a network. It provides social network theory with conceptual and analytical tools to analyze change, transformation and the future, in the context of networks. On the other hand, it gives futures studies conceptual and analytical tools to analyze one of the fundamental aspects of current social dynamics, namely networks. By combining them, both fields gain enormously in analytical strength and depth. The resulting new product, Futures Studies-Social Network Analysis, may become crucial to understanding the latest social phenomena and changes, as well as the emerging phenomena shaping the society or societies of tomorrow.

Social network analysis [15] yields a map of the interrelationships among actors/organizations that is useful for understanding and picturing the system of contacts and ties required to take action and convey information from one part of a network to another. Indicators such as centrality, closeness, and betweenness -the capacity to bridge different parts of the network - enable us to predict what the actors will do, while indicators such as cohesion and structural equivalence enable us to predict support or competition among actors. Even the concept of structural holes [16] aids in uncovering windows of opportunity, i.e. non-existent or empty relational spaces that can greatly benefit the actors who find them, and the networks in which they are embedded, leading to new relationships that contribute fresh and original resources to the network. In addition, social network analysis provides information that facilitates action [7] focused on generating change, since change is produced in networks by increasing or reducing centrality, accelerating or slowing down the flow of communication, and strengthening or weakening the network.

To start exploring the relation between Network Analysis and Futures Studies, I will use the classic and synthetic approach of probable, possible and preferable futures [3]. Their conceptual linkage to action brings them closer to social networks, seen as spaces and channels of action.

This popular and extensively used three dimensional vision of the future is well embedded in more complex methodological approaches $[17,18,19,14$, and 20]. These futures, as modes of thinking, are a fundamental part of the 
plurality of perspectives [8] making up Integral Futures [21]. They are also core elements in the six basic questions, six basic concepts and six basic pillars of the methodological approach proposed recently by Inayatullah [17]. This methodological vision of the future grants a special relevance to social networks in anticipating and making feasible and channeling alternative (possible) and desired (preferable) futures. This reduces the impact of colonization [14, 22] and control [23] of the future resulting from the use of lineal models of prediction centered on forecasting probable futures.

This three dimensional vision of the future also becomes useful to understand and shape action in the present. In fact, a "systematic and rigorous study of the possible, the probable, and the preferable would be joined to create a growing and widely followed science of social action to help people become more responsible" [24].

\section{Predicting the future: Probable (likely) Futures}

Network analysis yields information that can be useful for envisioning the future, making predictions [25] or determining the most likely future. Centrality indicators highlight the most prominent, powerful, well-known actors in a network. In some situations, information on centrality can point directly to the most likely future. This is the case when the prediction is focused on a matter that has a basis in relational aspects, for example, in the election of a pope.

After the death of John Paul II (on April 2, 2005), the Conclave of Cardinals put in motion the process that would lead to the election of Pope Benedict XVI on April 19, 2005. For more than two weeks, politics worldwide were affected by the election process and by the debates and information emerging about the future pope. All manner of political arguments and rumors were used to try to guess who the next pope would be. Curiously, no one made use of the one approach that could have been essential for making such a prediction: an analysis of knowledge-based trust and support. Focusing on this dimension, social network analysis offered a comparative advantage because it was able to provide information on the relational intensity and knowledge among the cardinals themselves. By analyzing the biographies of the cardinals attending the Conclave, it was possible, prior to the final decision, to obtain 
information on the relationships among them as members of the same congregation. Belonging to the same congregation improved contact, knowledge and trust among the cardinals. Those cardinals with more contacts, thanks to belonging to more congregations, would be better-known and would enjoy the confidence of a greater number of cardinals. This information would lead us directly to the people most likely to be elected pope by the Conclave.

Creating a visual representation of the relational system based on comembership in congregations (Graph 1) produces a highly dense, complex structure. The periphery is made up of cardinals who have fewer relationships and the closely woven centre shows where relations are most intense. The relational system's complexity and density makes it difficult to picture the center of the network clearly; however the center is the space where the cardinals most likely to be named pope are to be found. To picture the network's center more effectively, a diagram limited to the strongest ties is then shown (Graph 2). This diagram only shows cardinals who belong together to four or more congregations and it represents the core, the center of greatest influence, in the network of cardinals.

In this graph, we can now clearly picture the most central cardinals, i.e. the ones with the highest level of relationships with their peers, the ones who are most widely-known and those who enjoy the greatest trust. Visually, and using the various centrality indicators (degree, closeness, betweenness, clique centrality), we found the list and ranking of the most central cardinals, in order, to be: Martínez Somalo, Silvestrini, Ratzinger, Macharski, Szoka and Tomko. The highest likelihood was that the future pope would come from this group ${ }^{1}$.

Just as with other prediction methods, network analysis cannot provide a single, infallible prediction because the information on which it must be based is always limited. In this case, however, the analysis considerably reduced the central core of cardinals most likely to be elected pope, and Ratzinger occupies third place behind Cardinal Martínez Somalo and Cardinal Silvestrini. Having information on relations that are less visible and more spiritual, e.g. "contact

\footnotetext{
${ }^{1}$ The analysis, conducted some days before the final election of the pope (April 14, 2005), can be found online at http://www.ub.es/epp/redes/cardenales.htm.
} 
with God", would perhaps make for greater accuracy in identifying the cardinal who was elected in the end.

In situations where interaction and trust are the basis of actions and choices that will shape the future, network information and its analysis offer a highly rigorous approach to determining probable (likely) futures.

\section{Possible Futures}

Studying possible futures is one of the most interesting avenues in futures studies, addressing situations that may come to pass in the future depending on a set of determining factors $[26,5]$. The analysis of possible futures lies at the heart of futures studies, since it affords a set of signs, like traffic signals, that indicate which possibilities are most appealing. In fact, the most direct way of envisioning possible futures may be through the use of scenarios, which are coherent, plausible situations given a specific set of determining factors. Scenarios serve as reliable representations of possible and alternative futures [17].

Combining social network analysis and futures studies once again presents interesting possibilities. Building scenarios using social networks introduces the dimension of the future and forecasting into network analysis, making it a useful tool for taking action and building such futures. Adding scenarios and the notion of possible futures to network analysis provides this approach with a dimension that makes it possible to better understand networks as dynamic instruments and spaces of change. At the same time, it also brings a new dimension of analysis to futures studies by providing a new tool for building alternative futures.

To highlight this point, a brief analysis of the takeover bids for Endesa, the "number-one Spanish electricity supplier", will offer an example ${ }^{2}$ of how combining network analysis and scenario building helps in deepening

\footnotetext{
${ }^{2}$ Based on the work of Josep A. Rodríguez and Julián Cárdenas, looking at the role played by networks of economic power in takeover bids, using global corporative interlocking networks [27, 28].
} 
understanding, and aids in explaining, the final outcome of the lengthy acquisition process of Endesa [27, 28].

The acquisition process began on September 5 of 2005, and stretched over two years, becoming the focal point for much of the economic and political life of the country, and generated heated debates and clashes from many quarters. Gas Natural, a Spanish company as well, launched a public takeover bid, known as an OPA in Spanish, to gain total control of Endesa's share capital. On February 21 2006, the German energy group E.ON made a counterbid for Endesa that was far in excess of Gas Natural's OPA. On September 25 2006, the construction and services company Acciona burst into the battle between Gas Natural and E.ON, purchasing 10\% of Endesa. By January 2007, Acciona's holdings of Endesa stood at 24.9\%. On February 27 2007, the Italian energy group Enel also joined the fray, acquiring $2.99 \%$ of Endesa and increasing their holdings to $24.98 \%$ by March 12 . As a result of this jockeying for position and the intense debate and political and governmental wrangling at national and international levels, Gas Natural withdrew its bid on February 12007 and, on April 2, E.ON reached an agreement with Enel and Acciona to withdraw its rival offer in exchange for electricity assets in Europe. In the end, on October 5 2007, over 91\% of Endesa accepted the bid from Enel and Acciona, who then took over ultimate control of the electricity supplier.

The takeover bids for Endesa launched by Gas Natural, E.ON and Acciona-Enel, as well as the subsequent political, governmental and economic reactions, can be analyzed in the context of networks of economic power.

From the perspective of network analysis, when referring to protagonists and their social capital we focus on the groups, or networks, in which the individual corporations are embedded. In other words, we do not treat the corporations as independent, individual entities, but rather as parts of a new entity that could be dubbed as a mega-network corporation ${ }^{3}$. Doing this puts a different perspective on the corporations involved, seen now as a part of their

\footnotetext{
${ }^{3}$ A mega-network corporation is the network of corporations linked to a specific corporation with ties of a maximun distance of two steps (two steps egocentric network), that is to say, linked thanks to a maximun of one intermediary.
} 
broader networks, and it enables us to picture and analyze the size and position of the mega-network corporation, its social capital, and the relationships between the mega-network corporation and the corporate network worldwide.

The group, or mega-network corporation, that includes Gas Natural (a two steps egocentric network) which contains 37 corporations, of which $81 \%$ are Spanish. In addition, about $5 \%$ of the group's companies are based in France and another $5 \%$ in Italy. The E.ON group, which is a mega-network corporation, comprises 87 corporations and it is made up of German, French, Canadian and US companies. Of the 87 members of the group, $36 \%$ are German (like E.ON), 21\% are based in France and 15\% can be found in North America $^{4}$. The Acciona group, or mega-network corporation, contains 20 companies, 16 that are Spanish and the remaining four that are Dutch. The Enel group, or mega-network corporation, contains 24 corporations, half of which are Italian, while the rest are split between the United Kingdom and the Netherlands. The Endesa group, a mega-network corporation, includes 35 companies, of which $77 \%$ are Spanish and $14 \%$ are French.

The E.ON group differs from the Spanish groups in terms of its greater size, or number of actors, as it is tied directly or indirectly through directors, to more than twice the number of corporations as Gas Natural or Endesa. The two Spanish groups are of similar size in terms of the number of interconnected corporations, which are 37 and 35 , respectively. In addition, as can be seen from Graph 3, the two groups overlap in two-thirds of these corporations, essentially forming the same network. By contrast, the Enel and Acciona groups are smaller in size.

Analyzing possible future scenarios allows us to picture the resulting networks in each of these cases and evaluate them in terms of economic and political power. The three possible scenarios emerging from the takeover bids proposed are: (1) the acquisition of Endesa by Gas Natural, (2) its purchase by E.ON, and (3) its acquisition by Acciona and Enel.

Our starting point is the initial situation in 2006 of the actors involved and the respective mega-network corporations of Endesa, Gas Natural, Acciona,

\footnotetext{
${ }^{4}$ To be exact, $8 \%(7)$ are Canadian and 7\% (6) are based in the United States.
} 
Engel and E.ON. The resulting networks are the product of merging the networks of the companies launching takeover bids (Gas Natural, E.ON and Acciona-Enel) with Endesa's network and then aggregating their egocentric networks, that is to say bringing together their mega-network corporations. The three resulting scenarios show substantial differences in their characteristics as a network, specifically in terms of size, impact and composition.

The first possible scenario concerns Gas Natural's bid for Endesa. Had the gas company acquired Endesa, the new group, or new mega-network corporation, would have risen from 38 to 48 corporations in size. In the worldwide corporate network, the Gas Natural group represented $6 \%$ and its acquisition of Endesa would have increased that by $26 \%$ to $8 \%$. Graph 3, depicting the worldwide network, clearly shows the small growth resulting from merging the two mega-network corporations. The effect, however, is relatively limited because of the considerable overlap between the two original groups. In fact, both corporations largely form part of the same network, sharing corporate relationships across 25 companies. The fusion of their corporate networks would reinforce largely existing corporate relationships. As a result, the scenario would essentially result in entrenchment at the national level, strengthening national control.

In the second possible scenario, the purchase of Endesa by E.ON, the E.ON group would rise to 121 corporations from 87 , making the increase in number of corporations greater in this second takeover bid. All the corporations in the Endesa group represent additions to the E.ON group, introducing a total of 34 corporations into E.ON's sphere of contact and influence. At the time, the E.ON group made up $14.6 \%$ of the largest corporations in the world and the acquisition of Endesa would raise that figure to $20 \%$, representing an increase of $39 \%$ in its total number of corporations. As can be seen clearly in Graph 4, E.ON's takeover bid was a move to expand into Spain. The size of E.ON's network would increase and its composition would grow more diverse, benefiting from access to a geographic area to which it had not previously been connected. E.ON sought to occupy a blank space that would be a source of fresh, heterogeneous information with no overlaps, which is what Ronald Burt (1992) conceptualized as a structural hole. E.ON was pursuing a course of 
action to purchase social capital that would put it in a more competitive position, both in the corporate network and in the marketplace, but especially in the network. In terms of political logic, this scenario would make the Spanish electricity company more international as part of the German group.

Gas Natural's bid, on the other hand, involved overlapping ties, growth in intensity and minimal increase in size. E.ON's bid represented increases in size but not in intensity. Gas Natural's offer was an action aimed at control where contact already existed. Conversely, the aim of E.ON's offer was to build new ties and extend the network of contacts. The two different outcomes are the result of two differing visions and strategies towards the creation of networks and the positioning in the market. In the first bid the network is reinforced, whereas in the second bid the network is expanded-in short, intensity vs. size. E.ON's bid for Endesa involved an expansion of European networks, whereas Gas Natural's bid would have brought a consolidation and strengthening of the national network.

In the third possible scenario, Acciona and Enel acquire Endesa. The Acciona-Enel group would grow from 44 corporations to 66 , increasing by 22 companies, or jumping $50 \%$ in size. The Acciona-Enel group made up $7 \%$ of the worldwide network, but after the acquisition, the resulting mega-network corporation would represent $11 \%$ of the worldwide corporate network (Graph 5). The new Acciona-Enel-Endesa group would largely be composed of Spanish companies (45\%), but it would also include companies based in Italy (18\%), the Netherlands (15\%) and France (10\%). That would make it an international group, although centered in the south of Europe, and it would offer an alternative to the French-German axis posed by E.ON's bid. In political terms, the third scenario is a combination of the first two scenarios: it strengthens the national network while inserting Endesa into a wider European corporate network.

In the end, the third scenario was adopted, representing a middle path between the two initial proposals. As such, it also represents a middle way for resolving the political and economic conflicts generated by the two initial bids. The purchase of Endesa by Acciona-Enel serves to strengthen the Spanish energy network nationally at the same time that it internationalizes the company 
through its ties with Enel. In fact, the resulting structure is a mega-network corporation that is European in nature, but built upon a Spanish national foundation. The Gas Natural purchase scenario would have increased national strength at the expense of not becoming more international and/or European in nature. By contrast, in the E.ON case, the resulting mega-network corporation would have been international, but the dominant national base would have been German. The ultimate solution responds to two overarching political concerns and/or rationales at work at the time: the control of nation-states (the national character of the mega-network corporation) and Europeanization. It enables Endesa to play a key role at the European and international level without losing its national character.

By combining the scenario analysis tool from futures studies with network analysis, we can create a powerful new theoretical and methodological approach capable not only of benefiting the two disciplines, but also of becoming a suitable tool in the analysis of new types of social phenomena in the twenty-first century: a network society constructing the future.

\section{Choosing the future: Desirable (Preferable) Futures}

Blending futures studies and network analysis also becomes a powerful tool for defining and constructing desirable and/or preferable futures. Network analysis yields information on the structure that frames actions and shapes the future. As a result, it provides information that can be useful in building futures that are desirable. We can employ network analysis as an instrument of action to construct or de-construct relational structures so that they can lead us towards one future or another. Studying centrality, betweenness and cutpoints $[29,30]$ helps us identify situations of structural weakness or strength [31] where action might be needed in order to increase or decrease contact or communication, depending on the type of future that is desired. Since action is articulated over networks and in networks, it follows that the future will also take shape via networks.

In this section I will use the analyses of the March 11th Terrorist Network, connected to the Madrid bomb attack in March 2004, to identify the elements on which to base action in order to reach a desirable future in which the network 
has been substantially weakened. The central element characterizing our new society is, without doubt, the growth in the importance of networks, or relational systems, as a new organizational form, a new way to structure and to articulate collective action. In this sense, terrorist action takes on a form and scope never before seen and also very difficult to uncover [32, 33]. The New York attacks (9/11) [34] and the March 11th train bombings in Madrid in 2004 have clearly demonstrated the consolidation of networks as new organizational forms and new forms of action. By using press reports, we can construct a map of one portion of the network involved in the Madrid bombings to gain a picture-albeit an incomplete one-of the terrorist organization involved.

In an initial analysis ${ }^{5}$, we uncovered a complete network of 74 people. It was made up of people mentioned in police reports and press coverage in connection with the Madrid bombings (e.g. contacts, sources of information, logistics support, materials suppliers, explosives suppliers, etc.) and it featured the people who obviously played a fundamental part in the attack. The complete network is the relational structure produced by incorporating relationships of kinship, friendship and contact, connection to a telephone shop implicated in the attack, trust, and connection to the international terrorist network [35, 36, and 37].

The complete network is a complex structure (see Graph 6), but it is not highly dense and the proportion of existing direct relationships is only $9 \%$ of the total possible. Communication in the network flows between nearly all of the actors with little effort or social cost, with the exception of six who are disconnected. In addition, connecting all the actors, bar the disconnected ones, can be achieved with fewer than two intermediaries, on average. In Graph 6 we can distinguish a very central portion of the network, which has a greater number of relationships and more intense relationships as well, around which a simpler substructures and more isolated actors revolve. The heart of the complete network, which is the most strongly connected and cohesive substructure, contains the most central actors (1, 3, 7 and 41$)$, along with actor 11. Together, they make up the complete network's nerve center.

\footnotetext{
${ }^{5}$ José A. Rodríguez analyzed the 11-M terrorist network in La red terrorista del 11M, Revista Española de Investigaciones Sociológicas, 107(2004) [36].
} 
When we take out of the complete network the actors who participated directly as the perpetrators of the attack and/or who died later in the explosion in a flat in Leganés (DPLE ${ }^{6}$ ), a working-class suburb in the south of Madrid, it is apparent that the network after the attacks still survives, although its relational density has somewhat diminished and the distance between actors has grown. It is less compact than the complete network and two substructures are bridged by a single relation (see Graph 7). In the upper half of the graph, there is a substructure that is not very dense, nor does it exhibit very intense relationships. In the lower half, a highly cohesive substructure appears, coinciding with the substructure created on the basis of relationships with $\mathrm{Al}$ Qaeda and international terrorist activity. The strong core that remains active is this international nucleus. Its central actors are 7 and actor 11, and the actors with the greatest intermediation (betweenness) capability are 66, 40 and 7.

One of the features of networks, especially of terrorist networks, is their dynamism. The fact that they are non-strong networks is precisely what facilitates their dynamism and ability to rebuild. As a result, it is highly likely that the terrorist network involved has taken on a different form or that some of its parts have been rebuilt. However, assuming no significant changes in the situation, network analysis and the visual depiction it provides can become very powerful tools in directing anti-terrorist action [38, 39]. We can identify the relationships and the actors whose removal would cause the largest breakdown and fragmentation of the network and/or would most seriously weaken it by increasing the distance between the actors.

Without DPLE in the network after the attacks, there remains a set of relationships linking parts of the network and maintaining it still together. With these relationships eliminated, the network fragments (see Graph 8). This would be the case with the relationship between actors 66 and 40 , which, if severed, would break the link between the two large substructures that make up the network, the upper half and the lower half. Other relationships which continue to hold the network together and without which its fragmentation would increase are the existing ties between actor 66 and actors 21 and 22, and

\footnotetext{
${ }^{6}$ DPLE stands for the people considered to be Direct Perpetrators and/or those who later died in the Leganes Explosion.
} 
between actor 24 and actors 22 and 23. Eliminating them would split the upper substructure of the network in half. Although less visible, the relationships between actor 7 and actors 8, 40 and 59 would also suffer fragmentation.

In order to splinter and weaken the network, action can also be taken upon its individual actors, using the KeyPlayer program [29]. Removing actors $7,16,24,64,66$ and 40 would produce the greatest rupture in the network, creating isolated substructures and obviously limiting their ability to act and/or generate a network of action. In these terms, we can attest to the fact that actors 7, 24 and 66 maintain the key central relationships for the survival of the network without DPLE. If they are taken out of the network, it starts to splinter and grows substantially weaker (Graph 9). Another way to weaken the network without AMEL would be to eliminate the group of actors who are the most cohesive and have the most intense relationships. This group has ties to the $\mathrm{Al}$ Qaeda international terrorist network and is made up of actors $7,11,18,15,16$, 13 and 14.

Since the fundamental element of the new forms of terrorist organization is the network, which facilitates contact and planned action, the strategy for tackling it is to fragment or weaken it by removing key relationships or actors from the information flow. Bearing in mind that this is a network, particular significance falls to the actors who facilitate communication and hold the network together. As a consequence, splintering and weakening the network relies on eliminating these actors.

Network analysis can overcome the limitations of other types of analysis. It can identify both direct and strong relationships as well as indirect and weak ones. It can also identify the network as a whole: the weak spaces and strong spaces, spaces with high cohesion and spaces with high relational potential. Such information is also fundamental to define actions aimed at building the desirable future, whether by creating and strengthening positive networks or by weakening or breaking up negative ones. 


\section{CONCLUSIONS}

The new network society, in the process of constructing its future, is in need of the merging of these two theoretical approaches, Social Network Analysis and Futures Studies. This merger stands to improve our ability to engage in the prediction of likely futures, the analysis of possible futures and the construction of desirable futures. This merger is also very useful to understand change and dynamics in networks thanks to the introduction of the futures dimension.

Relationships are central in today's world and they shape what the future may become. As they make present communication and action possible they also shape the future system of communication. By yielding a map of the interactions between actors or entities shaping action, social network analysis can be useful in the study and construction of the future.

To the extent that actions take place over networks and in networks, the knowledge that network analysis provides us makes it possible to intervene in networks in order to produce changes and reach future goals. Action today is what builds tomorrow. Understanding social networks and social fabrics helps in taking actions now to construct the future, a future being built through actions in networks and over them.

Aknowlegments: This paper has greatly benefited from the comments and ideas of Wendell Bell, Julián Cárdenas, Anna Ramon, Joanne Vitello, Alex Rodríguez, and José Luis C. Bosch. It is based on research funded by the Spanish Ministry of Science and Innovation (SEJ2007-67714) and by the Catalan Government (2005SGR00368). 


\section{REFERENCES}

[1] S. Wasserman, K. Faust, Social Network Analysis: Methods and Applications, New York, Cambridge University Press, 1994.

[2] L. Freeman, D. White, A. Romney, Research Methods in Social Network Analysis, VA, George Mason University Press, 1989.

[3] W. Bell, Foundations of Future Studies, 2 volumes, New Jersey, Transaction Books, 1996.

[4] E. Masini, Why Future Studies, London, Grey Seal, 1993.

[5] E. Cornish, Futuring: The Exploration of the Future, Washington DC, World Future Society, 2004.

[6] M. Godet, Scenarios and strategic management, London, Butterworths, 1987.

[7] M. Godet, From anticipation to action: a handbook of strategic prospective, Paris, Unesco, 1994.

[8] J. Voros, Introducing a classification framework for prospective methods, Foresight, volume 8, number 2 (2006) 43-56.

[9] R. Burt, Toward a Structural Theory of Action, New York, Academic Press, 1982.

[10] H.C. White, Identity and Control: A Structural Theory of Social Action, New Jersey, Princeton University Press, 1992.

[11] R.L. Breiger, Social Mobility and Social Structure, Cambridge, Cambridge University Press, 1990.

[12] D.J. Watts, Small Worlds: The Dynamics of Networks between Order and Randomness, New Jersey, Princeton UP, 1999.

[13] M. Buchanan, Nexus: Small Worlds and the Groundbreaking Theory of Networks, New York, W.W. Norton, 2003.

[14] Z. Sardar, Rescuing All Our Futures: The Future of Future Studies, Connecticut, Praeger, 1999.

[15] R. Burt, M. Minor, Applied Network Analysis: A Methodological Introduction, Beverly Hills (CA), Sage, 1983.

[16] R. Burt, Structural Holes, Cambridge, Harvard University Press, 1992.

[17] S. Inayatullah, Six pillars: futures thinking for transforming, Foresight, volume 10, number 11 (2008) 4-21.

[18] R. Slaughter, The Knowledge Base of Future Studies, Australia, Media Group, 1996.

[19] J. Voros, A generalised "layered methodology" framework, Foresight, volume 7, number 2 (2005) 28-40.

[20] E. Blass, Researching the future: method or madness?, Futures, volume 35, number 10 (2003) 1041-1054. 
[21] J. Voros, Integral Futures: An approach to futures inquiry, Futures, volume 40 (2008) 190-201.

[22] K.W. Junher, How the future is cloned, in: Z. Sardar, Rescuing All Our Futures: The Future of Future Studies, Connecticut, Praeger, 1999.

[23] S. Inayatullah, Forming the shape and time of the future, in: R.A. Slaughter (Ed.) The knowledge Base of Future Studies, DDMMedia Group, Melbourne, 1996.

[24] W. Bell, Making people responsible: the possible, the probable and the preferable, in: J.A. Dator (Ed.), Advancing Futures: Future studies in higher education, Praeger, Connecticut, 2002.

[25] N. Rescher, Predicting the Future: An Introduction to the Theory of Forecasting, New York, SUNY Press, 1998.

[26] B. Schwartz, U. Suedin, B. Withroch, Methods in Futures Studies: Problems and Applications, Colorado, Boulder, Westview Press, 1982.

[27] J.A. Rodríguez, J. Cárdenas, Struggles for Power, XXV International Sunbelt Social Network Conference, Vancouver, British Columbia, Canada (April 2006).

[28] J.A. Rodríguez, J. Cárdenas, Politics and Interlockings, First ISA Forum of Sociology, Barcelona (September 2008).

[29] S. Borgatti, KeyPlayer 1.41 (http://www.analytictech.com/keyplayer.htm)

[30] S. Borgatti, M. Everett, L. Freeman, UCINET 6, Social Network Analysis Software (http://www.analytictech.com/ucinet.htm)

[31] M. Granovetter, The Strength of Weak Ties, American Journal of Sociology, volume 78, number 6 (1973) 1360.

[32] B. Erickson, Secret Societies and Social Structure, Social Forces, volume 60, number 1 (1981) 188-210.

[33] M. Sageman, Understanding Terror Networks, Pennsilvania, University of Pennsilvania, 2004.

[34] V. E. Krebs, Mapping Networks of Terrorist Cells, Connections, volume 24, issue 3 (2001) 43-52.

[35] J.A. Rodríguez, La red terrorista del 11M, Revista Española de Investigaciones Sociológicas, volume 107, number 4 (2004) 155-179. (http://estudiospoderprivilegio.googlepages.com/redessociales3)

[36] J.A. Rodríguez, The March $11^{\text {th }}$ terrorist network, XXV International Sunbelt Social Network Conference, Redondo Beach (CA), USA (March 2005).

[37] J.A. Rodríguez, Weakness and strengths of terrorist networks, 103rd Annual Meeting American Sociological Association, Boston (August 2008).

[38] K.M. Carley, S. Lee, D. Krackart, Destabilizing Networks, Connections, volume 24, issue 3 (2001) 31-34. 
[39] P. Fellman, R. Wright, Modeling Terrorist Networks- Complex Systems at the Mid-Range, The Intelligencer- Journal of US Intelligence Studies, Vol. 14, No. 1, Winter/Spring, 2004. (www.orgnet.com/hijachers.html). 